\title{
Comprehensive Geriatric Assessment in Oncology: Best Practices in Caring for Older Patients
}

\author{
JANINE OVERCASH, ${ }^{1}$ PhD, GNP-BC, FAANP, NIKKI FORD, ${ }^{2}$ BA, BSN, RN, OCN ${ }^{\circledR}$, \\ H. PAIGE ERDELJAC, ${ }^{2}$ PharmD, BCACP, SUSAN FUGETT, ${ }^{2}$ MSW, LISW-S, OSW-C, \\ BRITTANY KNAUSS, ${ }^{2} \mathrm{PT}$, DPT, CLT, ELIZABETH KRESS, ${ }^{2}$ CNP, CARI UTENDORF, ${ }^{2} \mathrm{PT}$, DPT, \\ MBA, CLT-LANA, and ANNE NOONAN, ${ }^{3}$ MD, MB BCh BAO, MSC, MRCPI
}

From 'College of Nursing, The Ohio State University, Columbus, Ohio; 2Stefanie Spielman Comprehensive Breast Center, The Ohio State University Comprehensive Cancer Center, Columbus, Ohio; 'Department of Internal Medicine, The Ohio State University Comprehensive Cancer Center, Columbus, Ohio

Authors' disclosures of conflicts of interest are found at the end of this article.

Correspondence to: Janine Overcash, PhD, GNP-BC, 1585 Neil Ave, Room 340 Newton Hall, Columbus, Ohio 43210.

E-mail: overcash.@@osu.edu

https://doi.org/10.6004/jadpro.2018.9.6.6 (c) 2018 Harborside $^{\text {TM }}$

\section{CASE STUDY}

Michele Green received the results of her breast cancer biopsy last week. Before surgery for infiltrating ductal carcinoma to her left breast, Michele was advised to meet with the members of the Senior Adult Oncology Program (SAOP) at the cancer center. A phone call from a nurse explained that the 2-hour visit with the SAOP would include meetings with many providers, such as a physical therapist, a social worker, a dietitian, a pharmacist, a nurse practitioner, and an oncologist to undergo a comprehensive geriatric assessment. Driving to her appointment, Michele wondered why her visit would take so long and why she had to see so many people. At 81 years old, Michele maintains her physical fitness and has never really been sick. She continues to work each week at the university and engages in an active social life. What could a team possibly find? Walking past the many examination rooms, Michele began to feel despair that she was now a "cancer patient." ancer is a disease of aging (Howlader et al., 2017). According to the Centers for Disease Control and Prevention, 38\% of people aged 65 years and over report they currently have or have had a diagnosis of cancer (Centers for Disease Control and Prevention, 2017). It is critical for advanced practitioners, including nurse practitioners (NPs), to consider how aging may impact cancer diagnosis and treatment. Older patients are a heterogeneous population spanning from those who are frail and dependent to those who are extremely fit and active. The oncology NP must be sensitive to the nuances of older patients and equipped to provide geriatric care. An element of best practice in geriatric oncology is to administer a comprehensive geriatric assessment (CGA), which is used to illustrate health beyond the 
traditional history and physical examination (Hurria et al., 2014; International Society of Geriatric Oncology, 2014; National Comprehensive Cancer Network, 2014; Overcash, 2013). The purpose of this article is to describe the CGA as used in a geriatric oncology ambulatory care clinic (GOACC) by a multidisciplinary team (MDT).

\section{COMPREHENSIVE}

\section{GERIATRIC ASSESSMENT}

A CGA is a battery of clinical assessment instruments used to screen for actual or potential health limitations in domains of functional, emotional, cognitive, nutritional, and physical health (International Society of Geriatric Oncology, 2017). Some examples of CGA instruments are the Timed Up and Go test (TUG; Podsiadlo \& Richardson, 1991), Activities of Daily Living scale (ADL; Katz, Downs, Cash, \& Grotz, 1970), Instrumental Activities of Daily Living scale (IADL; Lawton \& Brody, 1969), pain (McCaffery \& Beebe, 1989), falls (American Geriatrics Society, British Geriatrics Society, and American Academy of Orthopaedic Surgeons Panel on Falls Prevention, 2001), the Mini-Cog (Borson, Scanlan, Brush, Vitaliano, \& Dokmak, 2000), and the Geriatric Depression Scale (GDS; Yesavage et al., 1982). The intention of the CGA is to detect small issues before they magnify and contribute to declining independence and identify comorbidities that may preclude patients from cancer therapies or predispose patients to toxicity from cancer treatment. The CGA can help predict cancer treatment tolerance (Hamaker et al., 2014), mortality (Antonio et al., 2017), and enhance quality of life (Puts et al., 2017).

A CGA can be fashioned to include any number of clinical instruments. Instruments that measure functional, emotional, and cognitive status are generally the core components of the CGA (National Comprehensive Cancer Network, 2014). The CGA is used to establish a baseline before cancer treatment and at regular intervals $(3,6$, or 12 months) throughout therapy (International Society of Geriatric Oncology, 2014). A CGA can be used in smaller community oncology practices, academic medical centers, ambulatory care, and inpatient settings. To use CGA, a foundation must be created to provide sustainable, effective, and productive geriatric oncology care (Overcash, 2015).

\section{INFRASTRUCTURE NECESSARY TO}

\section{SUPPORT CGA}

Initiating CGA in any practice requires considerable planning (Burhenn et al., 2016; Overcash, 2015). Approval from facility administration to support longer outpatient encounter times is necessary when conducting a CGA. In addition, MDT organization, routes of referrals to address nonmalignant issues, and the makeup of the CGA are important considerations when creating the foundation for geriatric oncology care.

Generally, functional, emotional and cognitive status domains are the core features of a CGA using instruments such as the GDS, ADL/IADL, and Mini-Cog. Consider the facility resources that can be dedicated to CGA, especially when more screening instruments beyond the core domains are desired. Ambulatory care clinics allow limited encounter time, which impacts the number of clinical assessment instruments that can be incorporated into the CGA. When initiating CGA in a clinic, only include a few assessment instruments in order to gain proficiency in administering clinical tools.

Referrals to specialists or other providers are often necessary to address the recommendations as a result of conducting a CGA. Establish relationships with physical therapists (PTs), occupational therapists, internal medicine practices, and others who are willing to provide care or accept new patients. Become familiar with community resources that offer housekeeping, transportation, meals, and other supportive services. When patients screen positive on any of the clinical instruments, it is imperative that limitations are addressed.

\section{SENIOR ADULT ONCOLOGY PROGRAM AT THE STEFANIE SPIELMAN COMPREHENSIVE BREAST CENTER}

Combining geriatric care principles with oncology management is the prime feature of the Senior Adult Oncology Program (SAOP). Staffed by nurses, a PT, a social worker (SW), an NP, a medical oncologist, and a pharmacist, the MDT conducts a CGA that is the basis for oncology diagnosis and treatment for older people diagnosed with breast cancer. The CGA requires approximately 1 hour 
to complete and consists of a grip strength measurement, the TUG, ADL/ IADL, pain, falls, the Mini-Cog, and GDS (Yesavage et al., 1982). Each of the SAOP team members have a specific role in patient assessment and cancer management plan construction. The SW conducts a psychosocial assessment, the pharmacist reviews medication using the Beers Criteria (American Geriatrics Society, 2012), and the PT assesses strength and balance. The nurse evaluates the patient using the traditional cancer center nursing assessment and the medical oncologist reviews cancer history and other health data. The NP conducts a large amount of the CGA. All of the assessment information is discussed among the SAOP team members and a comprehensive cancer management plan is constructed.

The MDT conducts joint assessments in order to expedite the patient encounter. Often, three team members (NP, PT, and SW) interview the patient at once to reduce duplication of patient history questions and gain an understanding of other discipline evaluations. Upon completion of each of the evaluations, the team gathers for a patient huddle to exchange information and develop the patient management plan. Each of the MDT members completes their section of an after-visit summary that details the CGA findings, recommendations, and oncology treatment plan. Charting for each of the SAOP encounters reflects the CGA assessments complete with scores and interpretation. It is important to ensure that geriatric oncology care is reflected in the medical record and sent to other providers who also care for the patient.

\section{CASE STUDY CONTINUED}

After the death of her husband, Michele revealed to the SW that she experiences sadness, especially during the holidays. Surrounded by many friends, Michele has no family members and no caregiver. Using the CGA, Michele was found to have a positive depression screen (GDS) and was interested in engaging in a support group for breast cancer patients. The PT found that Michele had some weakness in her right leg as detected using the TUG, knee bends, and chair raises, which triggered the recognition of fall risk. Michele suggested that she does have trouble with her right knee. Michele reported she had no difficulty in achieving her
ADLs/IADLs. An assessment using the Mini-Cog revealed no difficulties drawing the clock with the correct time; however, some difficulty was experienced with the three-word recall. The pharmacist reviewed medications with several concerns. The nutritional screen did not reveal any deficits.

\section{CASE DISCUSSION}

At first glance, Michele did not appear impaired or even at risk for physical deterioration. Conducting a CGA detected small problems in lower extremity weakness that increase the risk for falls and general functional disability. The PT performed a brief evaluation, including manual muscle testing and the 30-second sit-to-stand test, revealing that Michele had weakness in her right leg. Physical therapy visits were scheduled for muscle strengthening to reduce the risk for falls.

The pharmacist updated the medication list and noted that she recently started amlodipine, which has a drug interaction with her simvastatin daily prescription that could increase the risk of muscle aches. The patient was taking diphenhydramine, which is listed on the Beers Criteria as a potentially inappropriate medication and should be avoided in people aged more than or equal to 65 years due to its anticholinergic effects that increase the risk of confusion, dry mouth, constipation, and other anticholinergic toxicities. The pharmacist encouraged the patient to stop taking diphenhydramine and instead try melatonin as needed for sleep.

The SW assessment revealed that since the death of her spouse, Michele cannot afford to fully retire as she spent most of her savings on upkeep of her home. Michele has no family locally and her support system is made up of causal friends and colleagues. After Michele's spouse died on Christmas day several years ago, she was diagnosed with depression, saw a psychotherapist, and was prescribed an antidepressant that she stopped taking. The SW encouraged Michele to consider completing her advance directives and to identify a healthcare proxy. The SW recommended Michele contact her NP to restart her antidepressant given her GDS score and known triggers for sadness around the holidays. Finally, the SW encouraged Michele to consider psychotherapy again and provided a list of local breast cancer support groups. 
Michele's mammogram and ultrasound of the right breast revealed a $1.2-\mathrm{cm}$ mass in the upper outer quadrant at 10 o'clock. Clinically, lymph nodes were negative and had no evidence of distant spread. Michele tolerated her right lumpectomy and sentinel lymph node biopsy very well and had no issues with anesthesia or wound healing. The final pathology revealed a $1.2-\mathrm{cm}$ grade 2 invasive ductal carcinoma and all three sentinel lymph nodes negative for metastases. An Oncotype DX genomic test used to assess the risk of recurrence (Genomic Health's Clinical Laboratory, 2017) was performed as the tumor size was $1.2 \mathrm{~cm}$, indicating a recurrence score of 15 and equating with a 10 -year risk of distant recurrence of $10 \%$ with tamoxifen alone. Given the superiority of aromatase inhibitors over tamoxifen in postmenopausal women, anastrozole was recommended. On the basis of her CGA, Michele was considered fit enough to tolerate cancer therapy. Her predicted life expectancy based on the National Comprehensive Cancer Network Guidelines for Older Adult Oncology (National Comprehensive Cancer Network, 2016) was 13 years as she was in the lowrisk category (Arias, 2012).

Due to the increased risk of osteoporosis with aromatase inhibitors, she had a baseline bone density scan performed. This revealed osteopenia of the left femoral neck with a T-score of -2.0 and normal bone density at the spine. The Fracture Risk Assessment (FRAX) tool revealed a 10-year risk of major osteoporotic fracture of $13 \%$ and hip fracture of $4.2 \%$; therefore, lifestyle modification was recommended, including weight-bearing exercise (University of Sheffield, 2008). Her vitamin D level was checked and found to be low. She was placed on a course of vitamin D and advised to take a calcium supplement.

\section{ROLE OF THE NURSE PRACTITIONER}

The advanced practitioner, including the NP, has several roles when using CGA in an oncology practice or an inpatient setting. Nurse practitioners manage every aspect of the care of many older patients and families by ordering diagnostic tests and interpreting laboratory values, addressing comorbidities, and managing symptoms. Especially for geriatric NPs, conducting a CGA is a main feature of the role and adding CGA screening instruments to the typical history and physical exam adds an important dimension to the patient evaluation. Nurse practitioners promote discussion among the MDT of CGA findings as they relate to the oncology evaluation. They assimilate the information, contribute to the medical record, communicate to other providers, and can help coordinate the GOACC. Nurse practitioners function differently depending on the type of oncology practice and whether the patients are encountered in an inpatient or outpatient setting. They have a critical role in offering care to older patients.

\section{CONCLUSION}

The CGA is an essential tool in delivering optimal care to older patients. With the senior population ( $\geq 65$ years) in the United States estimated to double by 2030 (Ortman, Velkoff, \& Hogan, 2014), the NP will play an increasingly pivotal role in coordinating care for the older oncology patient. Oncology care for older patients requires a more comprehensive approach that includes a CGA and a MDT. The NP offers the advanced skills that contribute to best practices in the care of the older adult.

\section{Disclosure}

The authors have no conflicts of interest to disclose.

\section{References}

American Geriatrics Society. (2012). American Geriatrics Society Updated Beers Criteria for potentially inappropriate medication use in older adults. Journal of the American Geriatrics Society, 60, 616-631. https://doi. org/10.1111/j.1532-5415.2012.03923.x

American Geriatrics Society, British Geriatrics Society, and American Academy of Orthopaedic Surgeons Panel on Falls Prevention. (2001). Guideline for the prevention of falls in older persons. Journal of the American Geriatrics Society, 49(5), 664-672. https://doi.org/10.1046/j.15325415.2001.49115.x

Antonio, M., Saldaña, J., Carmona-Bayonas, A., Navarro, V., Tebé, C., Nadal, M.,...Borràs, J. M. (2017). Geriatric assessment predicts survival and competing mortality in elderly patients with early colorectal cancer: Can it help in adjuvant therapy decision-making? Oncologist, 22(8), 934-943. https://doi.org/10.1634/theoncologist.2016-0462

Arias, E. (2012). United States Life Tables, 2008. National Vital Statistics Reports, 61(3). Retrieved from https://www. cdc.gov/nchs/data/nvsr/nvsr61/nvsr61_03.pdf

Borson, S., Scanlan, J., Brush, M., Vitaliano, P., \& Dokmak, A. (2000). The mini-cog: A cognitive 'vital signs' measure for dementia screening in multi-lingual elderly. International Journal of Geriatric Psychiatry, 15(11), 1021-1027. https:// doi.org/10.1002/1099-1166(200011)15:11\%3C1021::AIDGPS234\%3E3.0.CO;2-6 
Burhenn, P. S., McCarthy, A. L., Begue, A., Nightingale, G., Cheng, K., \& Kenis, C. (2016). Geriatric assessment in daily oncology practice for nurses and allied health care professionals: Opinion paper of the Nursing and Allied Health Interest Group of the International Society of Geriatric Oncology. (2016). Journal of Geriatric Oncology, 7(5), 315-324. https://doi.org/10.1016/j.jgo.2016.02.006

Centers for Disease Control and Prevention. (2017). Health, United States, 2016 - Individual charts and tables: Spreadsheet, PDF, and PowerPoint files. Retrieved from https://www.cdc.gov/nchs/hus/contents2016.htm

Genomic Health's Clinical Laboratory. (2017). Oncotype DX.

Hamaker, M. E., Seynaeve, C., Wymenga, A. N. M., van Tinteren, H., Nortier, J. W., Maartense, E.,...Smorenburg, C. H. (2014). Baseline comprehensive geriatric assessment is associated with toxicity and survival in elderly metastatic breast cancer patients receiving single-agent chemotherapy: Results from the OMEGA study of the Dutch Breast Cancer Trialists' Group. Breast, 23(1), 81-87. https://doi.org/10.1016/j.breast.2013.11.004

Howlader, N., Noone, A. M., Krapcho, M., Miller, D., Bishop, K., Kosary, C. L.,...Cronin, K. A. (eds). (2017). SEER Cancer Statistics Review, 1975-2014. National Cancer Institute. Retrieved from https://seer.cancer.gov/csr/1975_2014/

Hurria, A., Wildes, T., Blair, S. L., Browner, I. S., Cohen, H. J., deShazo, M.,...Sundar, H. (2014). Senior Adult Oncology, Version 2.2014: Clinical Practice Guidelines in Oncology. Journal of the National Comprehensive Cancer Network, 12(1), 82-126. https://doi.org/10.6004/jnccn.2014.0009

International Society of Geriatric Oncology. (2014). Comprehensive geriatric assessment. from http://www.siog.org/ content/comprehensive-geriatric-assessment-0

International Society of Geriatric Oncology. (2017). Comprehensive geriatric assessment (CGA) of the older patient with cancer. Retrieved from http://www.siog.org/content/comprehensive-geriatric-assessment-cga-olderpatient-cancer

Katz, S., Downs, T. D., Cash, H. R., \& Grotz, R. C. (1970). Progress in development of the index of ADL. Gerontologist, 10(1), 20-30. https://doi.org/10.1093/geront/10.1_Part_1.20
Lawton, M., \& Brody, E. M. (1969). Assessment of older people: Self-maintaining and instrumental activities of daily living. Gerontologist, 9(3), 179-186. https://doi. org/10.1093/geront/9.3_Part_1.179

McCaffery, M., \& Beebe, A. (1989). Pain: Clinical manual for nursing practice. Journal of Pain and Symptom Management, 5(5), 338-339. https://doi.org/10.1016/08853924(90)90052-L

National Comprehensive Cancer Network. (2014). NCCN Clinical Practice Guidelines in Oncology: Senior Adult Oncology. Retrieved from https://nccn.org

National Comprehensive Cancer Network. (2016). NCCN Clinical Practice Guidelines in Oncology: Older Adult Oncology. v1.2016. Retrieved from https://nccn.org

Ortman, J., Velkoff, V., \& Hogan, H. (2014). An aging nation: The older population in the United States. Retrieved from https://www.census.gov/prod/2014pubs/p25-1140.pdf

Overcash, J. (2013). Geriatric oncology nursing: Beyond standard care. Interdisciplinary Topics in Gerontology, 38, 139-145. https://doi.org/10.1159/000343610

Overcash, J. (2015). Integrating geriatrics into oncology ambulatory care clinics. Clinical Journal of Oncology Nursing, 19(4), E80-E86. https://doi.org/10.1188/15.CJON.E80-E86

Podsiadlo, D., \& Richardson, S. (1991). The timed "Up \& Go": A test of basic functional mobility for frail elderly persons. Journal of the American Geriatrics Society, 39(2), 142-148. https://doi.org/10.1111/j.1532-5415.1991.tb01616.x

Puts, M. T. E., Sattar, S., Kulik, M., MacDonald, M. E., McWatters, K., Lee, K.,...Alibhai, S. M. H. (2017). A randomized phase II trial of geriatric assessment and management for older cancer patients. Supportive Care in Cancer, 26(1), 109-117. https://doi.org/10.1007/s00520-017-3820-7

University of Sheffield. (2008). Fracture Risk Assessment Tool $\left(\right.$ FRAX $\left.^{\circledR}\right)$. Retrieved from https://www.sheffield. ac.uk/FRAX/

Yesavage, J. A., Brink, T. L., Rose, T. L., Lum, O., Huang, V., Adey, M., \& Leirer, V. O. (1982). Development and validation of a geriatric depression screening scale: A preliminary report. Journal of Psychiatric Research, 17(1), 37-49. https://doi.org/10.1016/0022-3956(82)90033-4 